\title{
Advanced liver imaging using MR to predict outcomes in chronic liver disease: a shift from morphology to function liver assessment
}

\author{
Francesco Verde, Valeria Romeo, Simone Maurea \\ Department of Advanced Biomedical Sciences, University of Naples “Federico II", Naples, Italy \\ Correspondence to: Valeria Romeo, MD, PhD. Department of Advanced Biomedical Sciences, University of Naples "Federico II", Via S. Pansini, 5, \\ 80131, Napoli, Italy. Email: valeria.romeo@unina.it.
}

Submitted Jan 17, 2020. Accepted for publication Jan 30, 2020.

doi: 10.21037/qims.2020.02.03

View this article at: http://dx.doi.org/10.21037/qims.2020.02.03

Chronic liver disease (CLD) or cirrhosis may result in hepatocellular carcinoma (HCC) and/or hepatic dysfunction. Although the development of HCC is the most important complication, liver failure has significant effects on morbidity and mortality (1). The assessment of hepatic functional reserve is relevant with significant implications in patient prognosis and management. Clinical and laboratory scoring systems such as the Child-Pugh classification as well as the Model for End-Stage Liver Disease (MELD) have been developed and are routinely applied; however, these scoring systems are limited in the assessment of hepatocyte function (2). In this setting, magnetic resonance imaging (MRI) has been proposed as a non-invasive imaging technique to assess and monitor liver and hepatocyte function through the application of paramagnetic hepatospecific contrast agent, particularly gadoxetic acid (GA). GA is a paramagnetic contrast agent characterized by a bi-phasic distribution in the interstitium and within hepatocytes through a selective uptake. Well-differentiated hepatocytes uptake the contrast agent and thus become bright in the hepatobiliary phase. As the GA uptake closely relates to hepatocyte activity, the hepatobiliary phase can be considered as a marker of liver function and its uptake is usually reduced in liver disease.

Recently, Bastati and colleagues (3) applied a functional liver imaging semiquantitative score (FLIS) derived from GA enhanced MRI to identify patients with CLD who are at increased risk for hepatic decompensation as well as for mortality predicting clinical outcome. According to clinical and laboratory data (i.e., fibrosis stage and previous/ current hepatic decompensation), patients were classified as nonadvanced CLD, compensated advanced CLD (CACLD) and decompensated advanced CLD (DACLD). Three imaging features in the hepatobiliary phase were included in the FLIS score as representative of liver function: i.e., (I) hepatic enhancement; (II) biliary excretion; (III) and signal intensity in the portal vein (3). FLIS resulted as independently predictive of hepatic decompensation in patients with CACLD and as an independent risk factor for mortality in both patients with CACLD and those with DACLD. Conversely, FLIS was not predictive of further hepatic decompensations in patients with DACLD. The authors concluded that FLIS is a simple non-invasive imaging marker for hepatic decompensation and transplantfree survival in patients with advanced CLD. These results are attractive and interesting.

At present, available scores to assess liver function in patients with CLD are mainly based on clinical and laboratory features, while routinely employed imaging techniques, i.e., ultrasound (US), computed tomography (CT), and/or conventional MRI, are able to assess morphological but not functional liver features. Morphological imaging changes often occur later in the course of liver disease (4). Advanced MRI has emerged as a comprehensive non-invasive diagnostic method to assess focal liver lesions and diffuse hepatobiliary disorders $(4,5)$. In detail, the chemical-shift sequence may be used to detect and estimate liver steatosis, while $\mathrm{T} 2{ }^{*}$ weighted images can be employed to quantify the iron content of liver parenchyma. Other advanced MRI techniques include diffusion and perfusion imaging, elastography, spectroscopy, susceptibility, and dynamic contrast-enhanced imaging (6). 
The introduction of liver-specific hepatobiliary contrast agents has expanded the role of MRI. In this regard, the amount of contrast concentration may be quantitatively estimated using static images by relative liver enhancement, hepatic uptake index, and relaxometry of T1-mapping during the hepatobiliary phase. Functional GA MRI evaluates patients who undergo surgery for liver malignancy or who may suffer after liver volume resection from postoperative remnant liver failure $(7,8)$; accurate estimation of the hepatic functional reserve is fundamental in such cases. The quantitative methods to assess hepatobiliary phase uptake on GA MRI, including relative liver enhancement, hepatic uptake index, contrast enhancement index, and T1 values, require complex computations which affects their clinical implementation (4). The semiquantitative FLIS using GA MRI proposed by Bastati and colleagues (3) seems to be easy to use, has the potential to be implemented in routine clinical practice to predict liver-related events (e.g., hepatic decompensation) and transplant-free survival in patients with different causes of CLD.

The results of Bastati et al. (3) are concordant with other experiences who found that decrease of GA uptake was associated with the development of hepatic decompensation in patients with compensated cirrhosis (9). Sandrasegaran et al. (10) showed that lower relative liver enhancement was a predictor for the development of hepatic decompensation and mortality in patients with cirrhosis. Of note, Bastati and colleagues initially evaluated the prognostic potential of GA-enhanced MRI using FLIS in orthotopic liver transplant grafts, providing qualitative imaging features that are independently associated with liver graft survival (11); in particular, FLIS might be used to evaluate patients with suspected liver graft dysfunction and select appropriate candidates for liver biopsy, and predict graft survival probability. With the same purpose, Pavlides et al. (12) proposed a similar score using MRI to predict clinical outcomes in patients with CLD, i.e., the liver inflammation and fibrosis (LIF) score reflecting normal, mild, moderate and severe liver disease. The score was able to provide valuable prognostic information in patients with CLD of mixed etiologies. In particular, this latter investigation expanded the results of a previous study from the same group (13) demonstrating that multiparametric MRI can be used to quantify liver fibrosis, iron and steatosis, each known to be a critical component in driving liver pathology.

Despite the study limitations, including its retrospective design as well as the lack of histologic confirmation of CLD, the results of Bastati et al. support the role of MRI offering prognostic information in CLD patients with semiquantitative imaging scores in a standardized approach. It is expected that a prospective multicenter study might be useful to confirm the clinical applications of FLIS using GA-enhanced MRI in functionally predicting the outcome of patients with CLD.

\section{Acknowledgments}

Funding: None.

\section{Footnote}

Conflicts of Interest: The authors have no conflicts of interest to declare.

Open Access Statement: This is an Open Access article distributed in accordance with the Creative Commons Attribution-NonCommercial-NoDerivs 4.0 International License (CC BY-NC-ND 4.0), which permits the noncommercial replication and distribution of the article with the strict proviso that no changes or edits are made and the original work is properly cited (including links to both the formal publication through the relevant DOI and the license). See: https://creativecommons.org/licenses/by-nc-nd/4.0/.

\section{References}

1. D'Amico G, Morabito A, D'Amico M, Pasta L, Malizia G, Rebora P, Valsecchi MG. Clinical states of cirrhosis and competing risks. J Hepatol 2018;68:563-76.

2. Ünal E, Akata D, Karcaaltincaba M. Liver function assessment by magnetic resonance imaging. Semin Ultrasound CT MR 2016;37:549-60.

3. Bastati N, Beer L, Mandorfer M, Poetter-Lang S, Tamandl D, Bican Y, Elmer MC, Einspieler H, Semmler G, Simbrunner B, Weber M, Hodge JC, Vernuccio F, Sirlin C, Reiberger T, Ba-Ssalamah A. Does the functional liver imaging score derived from gadoxetic acid-enhanced MRI predict outcomes in chronic liver disease? Radiology 2020;294:98-107.

4. Ba-Ssalamah A, Bastati N, Wibmer A, Fragner R, Hodge JC, Trauner M, Herold CJ, Bashir MR, Van Beers BE. Hepatic gadoxetic acid uptake as a measure of diffuse liver disease: where are we? J Magn Reson Imaging 2017;45:646-59.

5. Erra P, Puglia M, Ragozzino A, Maurea S, Liuzzi R, Sabino G, Barbuto L, Cuocolo A, Imbriaco M. Appearance 
of hepatocellular carcinoma on gadoxetic acid-enhanced hepato-biliary phase MR imaging: a systematic review. Radiol Med 2015;120:1002-11.

6. Wáng YXJ, Wang X, Wu P, Wang Y, Chen W, Chen H, Li $\mathrm{J}$. Topics on quantitative liver magnetic resonance imaging. Quant Imaging Med Surg 2019;9:1840-90.

7. Costa AF, Tremblay St-Germain A, Abdolell M, Smoot RL, Cleary S, Jhaveri KS. Can contrast-enhanced MRI with gadoxetic acid predict liver failure and other complications after major hepatic resection? Clin Radiol 2017;72:598-605.

8. Shen YN, Zheng ML, Guo CX, Bai XL, Pan Y, Yao WY, Liang TB. The role of imaging in prediction of posthepatectomy liver failure. Clin Imaging 2018;52:137-45.

9. Yoon JH, Lee JM, Kang HJ, Ahn SJ, Yang H, Kim E, Okuaki T, Han JK. Quantitative assessment of liver function by using gadoxetic acid-enhanced MRI: hepatocyte uptake ratio. Radiology 2019;290:125-33.

10. Sandrasegaran K, Cui E, Elkady R, Gasparis P, Borthakur G, Tann M, Liangpunsakul S. Can functional parameters

Cite this article as: Verde F, Romeo V, Maurea S. Advanced liver imaging using MR to predict outcomes in chronic liver disease: a shift from morphology to function liver assessment. Quant Imaging Med Surg 2020;10(3):805-807. doi: 10.21037/ qims.2020.02.03 from hepatobiliary phase of gadoxetate MRI predict clinical outcomes in patients with cirrhosis? Eur Radiol 2018;28:4215-24.

11. Bastati N, Wibmer A, Tamandl D, Einspieler H, Hodge JC, Poetter-Lang S, Rockenschaub S, Berlakovich GA, Trauner M, Herold C, Ba-Ssalamah A. Assessment of orthotopic liver transplant graft survival on gadoxetic acidenhanced magnetic resonance imaging using qualitative and quantitative parameters. Invest Radiol 2016;51:728-34.

12. Pavlides M, Banerjee R, Sellwood J, Kelly CJ, Robson MD, Booth JC, Collier J, Neubauer S, Barnes E. Multiparametric magnetic resonance imaging predicts clinical outcomes in patients with chronic liver disease. $\mathrm{J}$ Hepatol 2016;64:308-15.

13. Banerjee R, Pavlides M, Tunnicliffe EM, Piechnik SK, Sarania N, Philips R, Collier JD, Booth JC, Schneider JE, Wang LM, Delaney DW, Fleming KA, Robson MD, Barnes E, Neubauer S. Multiparametric magnetic resonance for the non-invasive diagnosis of liver disease. $\mathrm{J}$ Hepatol 2014;60:69-77. 